\title{
Successful Treatment of Generalized Eruptive Keratoacanthoma of Grzybowski with Acitretin
}

\author{
Hélène Mascitti · Adèle De Masson · Florence Brunet-Possenti • \\ Jean-David Bouaziz • Pauline Laly • Nadim Mourad • Jean-Michel Garrigues • \\ Sara Laurent-Roussel • Bénédicte Cavelier-Balloy • Isabelle Moulonguet • \\ Cristina Leschi · Samia Mourah · Martine Bagot · Céleste Lebbé · \\ Nicole Basset-Seguin
}

Received: January 2, 2019 / Published online: February 21, 2019

(C) The Author(s) 2019

\section{ABSTRACT}

Introduction: Keratoacanthomas (KA) are common cutaneous skin tumors originating from the hair follicles. Unlike squamous cell carcinoma, KA can regress spontaneously and have a benign evolution. Solitary KA is the most common form but familial multiple KA

Enhanced Digital Features To view enhanced digital features for this article go to https://doi.org/10.6084/ m9.figshare.7701632.

H. Mascitti · A. De Masson · J.-D. Bouaziz ·

P. Laly · N. Mourad - M. Bagot · C. Lebbé .

N. Basset-Seguin $(\square)$

Department of Dermatology, Saint-Louis Hospital,

AP-HP, INSERM U976, University of Paris 7 Paris

Diderot, Paris, France

e-mail: nicole.basset-seguin@aphp.fr

F. Brunet-Possenti

INSERM UMR-1137, IAME, Department of Virology, Bichat Hospital, University of Paris 7 Paris Diderot, Paris, France

J.-M. Garrigues

Dermatology Practice, Maisons-Laffitte, France

S. Laurent-Roussel · B. Cavelier-Balloy ·

I. Moulonguet

Department of Pathology, Saint-Louis Hospital, AP-

HP, University of Paris 7 Paris Diderot, Paris, France

C. Leschi $\cdot$ S. Mourah

AP-HP, Saint-Louis Hospital, Department of Pharmacogenomics, INSERM UMR-S 976, University of Paris 7 Paris Diderot, Paris, France
(Ferguson-Smith type), genetically predisposed KA (such as in xeroderma pigmentosum, or Muir-Torre syndrome), or sporadic multiple eruptive KA (Grzybowski type) have been described. Generalized eruptive KA of Grzybowski (GEKA) is a rare condition (around 40 reported cases). The pathophysiology is still unclear. Human papillomavirus (HPV) has been detected in sporadic KA but the presence of HPV39 has never been reported, to our knowledge, in GEKA.

Case Report: GEKA in an 80-year-old woman was successfully treated with acitretin $(0.5 \mathrm{mg} /$ $\mathrm{kg} /$ day) combined with surgical removal of the largest lesions. Treatment was well tolerated and led to decreased pruritus and tumor regression within 6 months. The presence of HPV39 was detected in a lesion by polymerase chain reaction and Sanger sequencing. No genetic alteration was found, in particular in the genes usually altered in squamous cell carcinoma (including NOTCH1, NOTCH2, CDKN2A, TP53).

Conclusion: We report a case of GEKA associated with the presence of HPV39 and the successful use of acitretin combined with surgical removal of the larger lesions.

Keywords: Acitretin; GEKA; Generalized eruptive keratoacanthoma of Grzybowski; HPV; Human papillomavirus 


\section{INTRODUCTION}

Keratoacanthomas (KA) are common cutaneous skin tumors originating from the hair follicles [1]. The lesions present typically as crateriform tumors and are more frequent in men [2]. Unlike squamous cell carcinoma (SCC), KA has a spontaneously regressive, benign evolution [3]. Solitary KA is the most common form but there are rare cases of familial multiple KA (Ferguson-Smith type [4]), genetically predisposed KA (such as in xeroderma pigmentosum [5], or Muir-Torre syndrome [6]), or sporadic multiple eruptive KA (Grzybowski type). Generalized eruptive KA of Grzybowski (GEKA) was first described in 1950 [7]. About 40 cases have been reported. Nofal et al. [8] proposed the following consistent diagnostic criteria: onset in adulthood (usually in the fifth to seventh decade of life); generalized eruption of hundreds to thousands of well-demarcated papules, some with a keratotic center; progressive course; severe and persistent pruritus; histopathological examination consistent with $\mathrm{KA}$; and lack of family history of multiple KA. The presence of a masked face ("mask of Zorro" sign), mucosal lesions, ectropion, and crateriform nodules have been suggested as variable criteria [8].

The lesions are typically widespread but predominate in sun-exposed areas [9]. The etiology of eruptive KA remains unknown. Radiation [10], immunosuppression [11], skin trauma [12], and treatments with BRAF [13] and Sonic Hedgehog pathway inhibitors have been reported as potential risk factors. A viral trigger has been proposed. Human papillomavirus (HPV) has been detected in sporadic KA [14-16] but the presence of HPV39 has never been reported, to our knowledge, in GEKA.

\section{CASE REPORT}

We present the case of a woman in her 80s with a GEKA who presented with a 6-month history of extremely pruritic lesions. Informed consent was obtained from the individual participant included in the study. She reported the sudden onset of hundreds of 1- to 3-mm scaly papules located on her legs, arms, and trunk, without any identified trigger. A few days after an emotional shock, some of the lesions had evolved into large crateriform tumors (Fig. 1a-c). She had no familial medical history but had a personal history of hypertension, depression, and sun exposure. She had been previously treated with antihistamines, topical corticosteroids, and 20 sessions of phototherapy without success. The phototherapy was initially prescribed for suspected prurigo but was followed by a worsening of the skin lesions.

There were numerous follicular papules with keratotic centers, erythematous nodules on the legs, arms, and trunk, and ten $1.5-$ to $3.5-\mathrm{cm}-$ diameter crateriform tumors of the limbs. The physical examination did not show mucosal involvement, sclerotic skin changes, or lymphadenopathy. There was no deterioration of her general condition. A full-body computed tomography (CT) scan was within normal limits. Blood work revealed negative results for her human immunodeficiency virus serology and a normal complete blood cell count. A biopsy specimen was obtained from one of the skin tumors (Fig. 2a, b). Histopathological examination of the specimen obtained from the patient's leg revealed a crater-shaped squamous proliferation connected to the epidermis and penetrating the dermis, with a central keratin plug (Fig. 2a). The keratinocytes were large and surrounded by a moderately abundant inflammatory infiltrate (Fig. 2b).

Molecular detection of $H P V$ was performed on the skin sample by polymerase chain reaction using degenerate primers, followed by Sanger sequencing [17]. One $\alpha$-HPV was detected: HPV type 39.

No genetic alteration was found in the genes usually altered in SCC (including NOTCH1, NOTCH2, CDKN2A, TP53) [18] on a lesional skin biopsy using a homemade next-generation sequencing panel covering skin carcinoma genes (90 genes). The patient was not screened for mismatch repair gene alterations ( $M L H 1$, MSH2, and MSH6) because she had not developed any other neoplasm associated with Muir-Torre syndrome. In particular, there was no history of sebaceous tumors.

The largest skin lesions were surgically removed and oral acitretin was started $(0.5 \mathrm{mg} /$ 

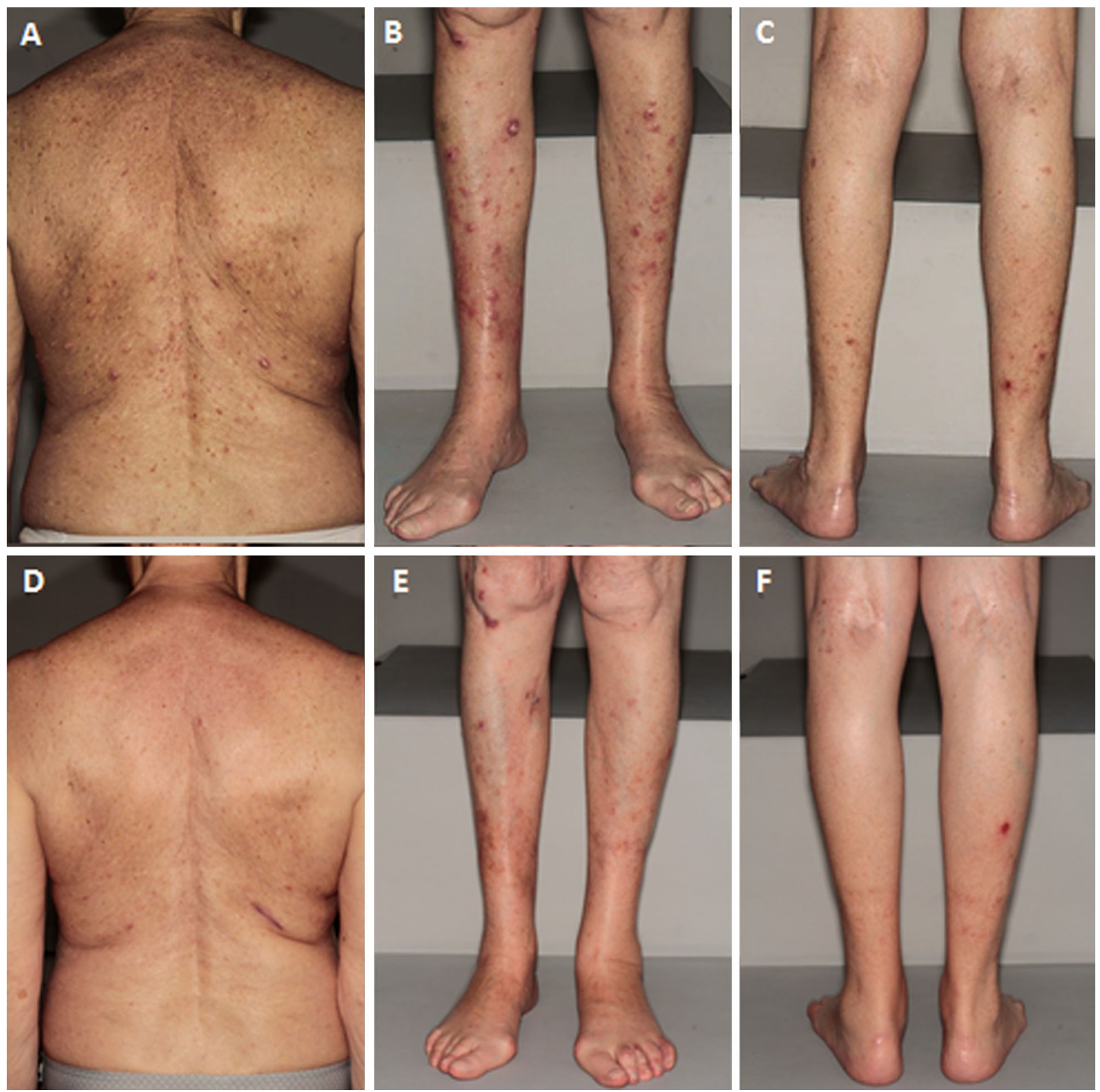

Fig. 1 Clinical pictures of the patient at the time of diagnosis, and 3 months after the initiation of oral acitretin. a Large tumors and scaly papules of the back at the time of diagnosis. $\mathbf{b}$ Large crateriform tumors (keratoacanthomas) and scaly papules of the anterior legs at the time of diagnosis. c Itchy pinky papules of the

$\mathrm{kg}$ /day), allowing a decrease in pruritus and the disappearance of numerous lesions (Fig. 1d-f). No new KA appeared under acitretin. She has been successfully treated with acitretin for 1 year.

posterior legs at the time of diagnosis. $\mathbf{d}$ Regression of the lesions of the back after 3 months of oral acitretin. e Regression of the lesions of the anterior legs after 3 months of oral acitretin. $\mathbf{f}$ Regression of the lesions of the posterior legs after 3 months of oral acitretin

\section{DISCUSSION}

Here, we report a new case of GEKA associated with the presence of HPV39. GEKA is a rare skin disease for which the pathophysiology remains 

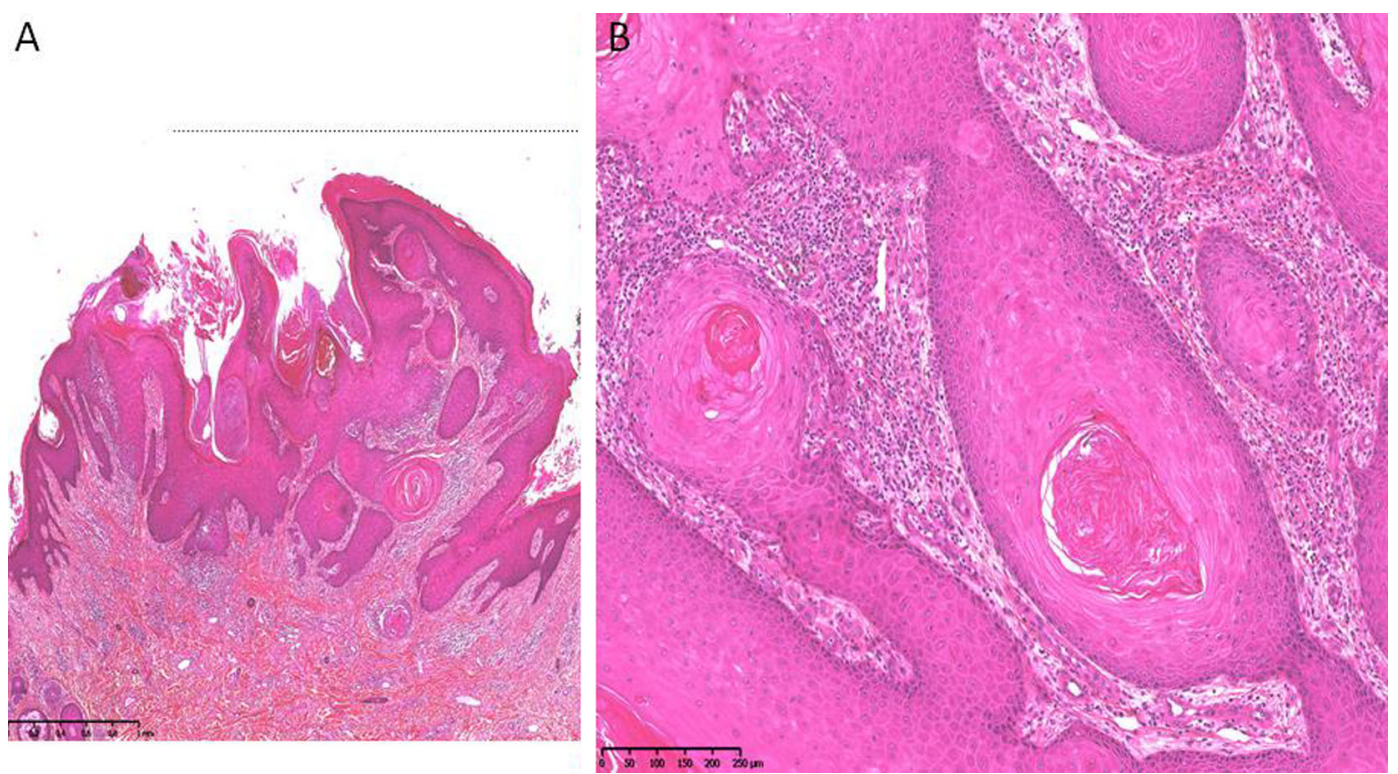

Fig. 2 Histopathological examination of a keratoacanthoma of the back with a central keratin-filled crater. a HES, $\times 3$. b Tumor nests with central keratin plugs, large eosinophilic keratinocytes, without atypia (HES, $\times 0$ )

unclear. KA is in most cases solitary and sporadic, and the etiology of the sudden onset of multiple KA in GEKA is unknown.

Histopathological examination of a $\mathrm{KA}$ is necessary to rule out the differential diagnoses of crateriform papules or nodules, including SCC, amelanotic melanoma, CD30 ${ }^{+}$anaplastic lymphoma, giant molluscum contagiosum, and hypertrophic lichen planus. Distinguishing KA and SCC can be challenging, particularly on a limited skin biopsy. KA are exo-endophytic lesions with an invaginating keratin-filled crater with a symmetrical epidermal proliferation at the sides and bottom of the lesion. Nuclear atypia and mitotic activity are rare, unlike in SCC [17]. Surgical excision with margins of $5 \mathrm{~mm}$ is the rule for solitary KA. Treatment of GEKA has not been uniformly satisfactory. Acitretin $(0.5-1 \mathrm{mg} / \mathrm{kg})$ is usually proposed as firstline treatment [19-21]. Methotrexate [22-24], topical 5-fluorouracil [21], cyclophosphamide $[25,26]$, and erlotinib $[27,28]$ are other reported therapeutic options. Here, acitretin combined with a surgical procedure was used successfully.

More than 200 different types of HPV have been identified [29]. HPV are classified into five genera: $\alpha, \beta, \gamma, \mu, v$. The role of $\alpha$-papillomavirus in the oncogenesis of SCC is well known [30]. Epidemiologically, the mucocutaneous HPV types can be subdivided on the basis of whether they are associated with benign or malignant lesions [31]. Low-risk HPV (HPV6 and HPV11) have been detected in two cases of sporadic KA $[15,16]$ but the presence of high-risk HPV has never been reported, to our knowledge, either in KA or GEKA. HPV39 belongs to the oncogenic, high-risk $\alpha$-papillomavirus types which are associated with a high risk of neoplasia (cervical, anal, vaginal, vulvar, penile, and oropharyngeal cancers and associated precursor lesions).

Interestingly, here, no genetic alteration was found in the genes usually affected in skin SCC, which suggests that KA and SCC have distinct pathogenetic mechanisms.

One of the limitations of our report is that the presence of HPV has only been studied in lesional skin and thus its presence may be coincidental. However, HPV39 is rarely found in healthy skin [32]. More studies are needed to explore the potential oncogenic role of HPV39 in KA. 


\section{CONCLUSIONS}

GEKA is a rare condition for which the pathophysiology is still unclear. To our knowledge, this is the first documented case of GEKA associated with HPV39. The potentially central role of this oncogenic $\alpha$-papillomavirus in the pathophysiology of GEKA warrants further investigation. Interestingly, no genetic alteration was found in our patient's tumor, which may explain its benign course.

\section{ACKNOWLEDGEMENTS}

We thank the participant of the study.

Funding. No funding or sponsorship was received for this study or publication of this article.

Authorship. All named authors meet the International Committee of Medical Journal Editors (ICMJE) criteria for authorship for this article, take responsibility for the integrity of the work as a whole, and have given their approval for this version to be published.

Disclosures. Hélène Mascitti, Adèle De Masson, Florence Brunet-Possenti, Jean-David Bouaziz, Pauline Laly, Nadim Mourad, JeanMichel Garrigues, Sara Laurent-Roussel, Bénédicte Cavelier-Balloy, Isabelle Moulonguet, Cristina Leschi, Samia Mourah, Martine Bagot, Céleste Lebbé and Nicole Basset-Seguin have nothing to disclose.

Compliance with Ethics Guidelines. Informed consent was obtained from the individual participant included in the study.

Open Access. This article is distributed under the terms of the Creative Commons Attribution-NonCommercial 4.0 International License (http://creativecommons.org/licenses/ by-nc/4.0/), which permits any noncommercial use, distribution, and reproduction in any medium, provided you give appropriate credit to the original author(s) and the source, provide a link to the Creative Commons license, and indicate if changes were made.

\section{REFERENCES}

1. Schwartz RA. Keratoacanthoma: a clinico-pathologic enigma. Dermatol Surg. 2004;30(2):326-33 (discussion 333).

2. Vergilis-Kalner IJ, Kriseman Y, Goldberg LH. Keratoacanthomas: overview and comparison between Houston and Minneapolis experiences. J Drugs Dermatol. 2010;9(2):117-21.

3. Mandrell JC, Santa Cruz D. Keratoacanthoma: hyperplasia, benign neoplasm, or a type of squamous cell carcinoma? Semin Diagn Pathol. 2009;26(3):150-63.

4. Smith JF. A case of multiple primary squamouscelled carcinomata of the skin in a young man, with spontaneous healing. $\mathrm{Br} \mathrm{J}$ Dermatol. $1934 ; 46(6): 267-72$.

5. Han X'e, Jing H, Liu C, Zheng J. Clinicopathological characteristics of xeroderma pigmentosum associated with keratoacanthoma in an infant. J Cancer Res Ther. 2015;11(3):665.

6. Schwartz RA, Torre DP. The Muir-Torre syndrome: a 25-year retrospect. J Am Acad Dermatol. 1995;33(1):90-104.

7. Grzybowski M. A case of peculiar generalized epithelial tumours of the skin. Br J Dermatol Syph. 1950;62(7-8):310-3.

8. Nofal A, Assaf M, Nofal E, Alradi M. Generalized eruptive keratoacanthoma: proposed diagnostic criteria and therapeutic evaluation. J Eur Acad Dermatol Venereol. 2014;28(4):397-404.

9. Wu TP, Miller K, Cohen DE, Stein JA. Keratoacanthomas arising in association with prurigo nodules in pruritic, actinically damaged skin. J Am Acad Dermatol. 2013;69(3):426-30.

10. Robertson SJ, Bashir SJ, Pichert G, Robson A, Whittaker S. Severe exacerbation of multiple selfhealing squamous epithelioma (Ferguson-Smith disease) with radiotherapy, which was successfully treated with acitretin. Clin Exp Dermatol. 2010;35(4):e100-2.

11. Dessoukey MW, Omar MF, Abdel-Dayem H. Eruptive keratoacanthomas associated with immunosuppressive therapy in a patient with systemic lupus 
erythematosus. J Am Acad Dermatol. 1997;37(3 Pt 1):478-80.

12. Pattee SF, Silvis NG. Keratoacanthoma developing in sites of previous trauma: a report of two cases and review of the literature. J Am Acad Dermatol. 2003;48(2 Suppl):S35-8.

13. Anforth R, Fernandez-Peñas P, Long GV. Cutaneous toxicities of RAF inhibitors. Lancet Oncol. 2013;14(1):e11-8.

14. Matoso A, Fabre V, Quddus MR, et al. Prevalence and distribution of 15 high-risk human papillomavirus types in squamous cell carcinoma of the scrotum. Hum Pathol. 2016;53:130-6.

15. Saftic M, Batinac T, Zamolo G, et al. HPV 6-positive giant keratoacanthoma in an immunocompetent patient. Tumori. 2006;92(1):79-82.

16. Niebuhr M, Gutzmer R, Hirschfeld D, et al. Giant keratoacanthoma in an immunocompetent patient with detection of HPV 11. Hautarzt. 2009;60(3):229-32.

17. Forslund O, Antonsson A, Nordin P, Stenquist B, Hansson BG. A broad range of human papillomavirus types detected with a general PCR method suitable for analysis of cutaneous tumours and normal skin. J Gen Virol. 1999;80(Pt 9):2437-43.

18. Pickering CR, Zhou JH, Lee JJ, et al. Mutational landscape of aggressive cutaneous squamous cell carcinoma. Clin Cancer Res. 2014;20(24):6582-92.

19. Sami N, Bussian A. Acitretin induces remission in generalized eruptive keratoacanthoma of Grzybowski. Int J Dermatol. 2015;54(2):e67-9.

20. Sachse MM, Fenchel K, Wagner G. Regression of B-RAF inhibitor associated keratoacanthomas by acitretin-how do retinoids act on the RAF/MEK/ ERK-signaling pathway? J Dtsch Dermatol Ges. 2014;12(8):721-3.

21. LaPresto L, Cranmer L, Morrison L, Erickson CP, Curiel-Lewandrowski C. A novel therapeutic combination approach for treating multiple vemurafenib-induced keratoacanthomas: systemic acitretin and intralesional fluorouracil. JAMA Dermatol. 2013;149(3):279-81.

22. Yoo MG, Kim I-H. Intralesional methotrexate for the treatment of keratoacanthoma: retrospective study and review of the Korean literature. Ann Dermatol. 2014;26(2):172-6.

23. Bieber AK, Cohen DE, Stein JA. Systemic methotrexate for prurigo nodularis and keratoacanthomas in actinically damaged skin. JAAD Case Rep. 2016;2(3):269-71.

24. Nofal A, Assaf M, Ghonemy S, Nofal E, Yosef A. Generalized eruptive keratoacanthoma: a diagnostic and therapeutic challenge. Int J Dermatol. 2015;54(2):160-7.

25. Grine RC, Hendrix JD, Greer KE. Generalized eruptive keratoacanthoma of Grzybowski: response to cyclophosphamide. J Am Acad Dermatol. 1997;36(5 Pt 1):786-7.

26. Oakley A, Ng S. Grzybowski's generalized eruptive keratoacanthoma: remission with cyclophosphamide. Australas J Dermatol. 2005;46(2):118-23.

27. Bulj TK, Krunic AL, Cetner AS, Villano JL. Refractory aggressive keratoacanthoma centrifugum marginatum of the scalp controlled with the epidermal growth factor receptor inhibitor erlotinib. Br J Dermatol. 2010;163(3):633-7.

28. Reid DC, Guitart J, Agulnik M, Lacouture ME. Treatment of multiple keratoacanthomas with erlotinib. Int J Clin Oncol. 2010;15(4):413-5.

29. Van Doorslaer K, Chen Z, Bernard H-U, et al. ICTV virus taxonomy profile: Papillomaviridae. J Gen Virol. 2018;99(8):989-90.

30. Olivero C, Lanfredini S, Borgogna C, Gariglio M, Patel GK. HPV-induced field cancerisation: transformation of adult tissue stem cell into cancer stem cell. Front Microbiol. 2018;9:546.

31. Cubie HA. Diseases associated with human papillomavirus infection. Virology. 2013;445(1-2): 21-34.

32. Bolatti EM, Chouhy D, Hošnjak L, et al. Natural history of human papillomavirus infection of sunexposed healthy skin of immunocompetent individuals over three climatic seasons and identification of HPV209, a novel betapapillomavirus. J Gen Virol. 2017;98(6):1334-48. 